University of Nebraska - Lincoln

DigitalCommons@University of Nebraska - Lincoln

$4-2-2021$

\title{
From Negotiator to Note-Taker: The Role of Women Leaders and Academic Technology Cultures
}

Leslie Zenk

University of North Carolina at Charlotte, Izenk@uncc.edu

Susan Harden

University of North Carolina at Charlotte, sharden@uncc.edu

Follow this and additional works at: https://digitalcommons.unl.edu/jwel

Part of the Educational Administration and Supervision Commons

Zenk, Leslie and Harden, Susan, "From Negotiator to Note-Taker: The Role of Women Leaders and Academic Technology Cultures" (2021). Journal of Women in Educational Leadership. 275.

https://digitalcommons.unl.edu/jwel/275

This Article is brought to you for free and open access by the Educational Administration, Department of at DigitalCommons@University of Nebraska - Lincoln. It has been accepted for inclusion in Journal of Women in Educational Leadership by an authorized administrator of DigitalCommons@University of Nebraska - Lincoln. 
Journal of Women in Educational Leadership, 2021

doi: 10.32873/unl.dc.jwel.199

http://digitalcommons.unl.edu/jwel/

ISSN 2379-2191

Journal of

Women in

Educational

\title{
From Negotiator to Note-Taker: The Role of Women Leaders and Academic Technology Cultures
}

\author{
Leslie R. Zenk \& Susan Harden
}

University of North Carolina at Charlotte

\begin{abstract}
For years, there has been a perceived inaccessibility of the field of Information Technology, centering on an organizational culture of "men and their machines" (Clark, 2012). This paper examines the role of women who lead technology initiatives in higher education and presents the experiences of these women leaders and their collision of organizational cultures as part of a comparative case study of two public institutions. Findings suggest elements of culture within the IT field that contribute to the experiences of women leaders in IT, and illuminate that leading a technology project may add a layer of gender expectations and gender roles that are more entrenched in the IT world than in other areas of higher education.
\end{abstract}

Keywords: leadership, higher education, women, information technology, culture

The well-established notion of "the higher, the fewer" (Nidiffer, 2002) describes that the higher one travels in the hierarchy of academia, the less likely they are to see women in those roles. This phenomenon is particularly noteworthy in information technology (IT) in higher 
education where not only have there been no significant gains in the percentage of women Chief Academic Officers (CIOs) in recent years (Brown, 2013; Clark, 2013; Woo \& McIntosh, 2016), but from 2008 to 2013 the number of women CIOs actually declined five percent from $26 \%$ to $21 \%$ (Center for Higher Education CIO Studies, 2013). Recent data reflects this percentage continued to decline to $20 \%$ in 2015 (Woo \& McIntosh, 2016).

Clark (2013) argues that bias within the pipeline plays a role in the lack of women in IT leadership. For years, there has been a persistent perception regarding the inaccessibility of the field of IT, centering on an organizational culture of "men and their machines" (Clark, 2012). These phenomena are in sharp contrast to the intense effort to recruit women into technology majors and place diverse IT graduates in industry (see National Center for Women \& Information Technology, 2019). It is ironic that higher education's external focus on equity emphasized at the institutional level is not matched internally within the IT organization. In order to address this incongruence, higher education leadership must understand the lived experiences of women in middle-management IT roles as these roles are professional stepping stones for most CIO positions. This paper, therefore, examines the role of women who lead technology initiatives in higher education as they navigate this labyrinth of organizational cultures. As context for this examination of women leading technology initiatives in higher education, we broaden the scale of our literature review to better understand the representation of women leadership in two settings: "Women Leaders in Higher Education" and "Women Leaders in Information Technology." Furthermore, we believe that an intersectional understanding of research in Gender and Leadership and Organizational Culture in Higher Educational helps to frame this study.

\section{Review of Literature}

\section{The Representation of Women in Leadership in Higher Education}

For many years, the "pipeline myth" was perpetuated within higher education: the idea that there are too few women in the pipeline to fill the 
number of leadership positions necessary. The pipeline myth was often described as the reason why women were less represented in university leadership positions. Recent data, however, including that described in the 2016 report by the American Council on Education (ACE) on the status of women in higher education revealed that there are more than enough qualified women in the pipeline for leadership positions (Johnson, 2016). In fact, women are being prepared at a greater rate than men; women have earned more than $50 \%$ of all doctoral degrees since $2006,50 \%$ of all master's degrees since 1991 , and $50 \%$ of all bachelor's degrees since 1981 (Johnson, 2016). Despite this, women are not obtaining senior-level positions, including full professor, at the same rate as their male peers, and women hold a greater share of service, entry-level, and teaching-only (less prestigious) positions: "As of 2014, women hold $31 \%$ of the full professor positions at degree-granting postsecondary institutions" (Johnson, 2016, p.5). Similarly, despite the fact that women presidents are more likely to have Ph.D.s or Ed.D.s compared to their male counterparts, women only hold $27 \%$ of presidencies across all institutions in the U.S. and men outnumber women on governing boards 2 to 1 . Reid Sarkees (2008) points out that women who do succeed in leadership roles face challenges related to their low numbers in positions of influence and that it is particularly difficult for members of minority groups to have influence in organizations that are skewed. Johnson (2016) describes the pay implications for all these discrepancies: men out earn women by $\$ 13,616$ at public institutions. There are two notable exceptions to the pay discrepancy however, as illustrated in a recent 2017 CUPA-HR study: Chief Facilities Officers and Chief Information Officers (Bischel \& McChesney, 2017). Bischel and McChesney (2017) speculate that in situations in which women are significantly underrepresented such as Chief Information Officer (CIO) or Chief Facilities Officer, institutions are recognizing the need to recruit and retain women to these important leadership positions by offering equal pay.

While there has been a notable increase in women leaders in higher education overall (the percentage of women presidents in U.S. institutions rose from $9 \%$ to $23 \%$ between 1986-2006), “... both research and the experience of women university leaders suggest that the culture and climate in which we make our careers still cast a negative light on our 
gender" (Catalyst, 2007, p.5). Dominici, Fried, and Zeger's (2009) focus group of 27 senior women faculty found that the pathways to leadership are slower and often blocked for women. Women are not recruited to leadership roles and often participate at a higher rate in leadership positions that do not follow what is perceived as the standard route to higher levels of leadership including directors of academic programs, committee chairs, and heads of centers and institutes.

\section{Women Leaders and Information Technology}

After years of a steady decline nationally in the the number of women CIOs (Brown, 2013; Clark, 2013; Woo \& McIntosh, 2016), 2019 saw an uptick in the percentage of women CIOs at large firms - up to $18 \%$ from $16 \%$ in 2017 according to a recent report by consulting firm Korn Ferry (2019). Within higher education, the percentages are slightly higher; data from the College and University Professional Association for Human Resources (CUPA) indicates that in 2015, 20\% of CIOs in higher education were women (Woo \& McIntosh, 2016). According to Clark (2012), "CIOs ... make decisions about their organizational" composition and culture, and yet they constitute the least diverse segment of IT's overall population" (p.1). Similarly to women in higher education more broadly, the pipeline also does not appear to be the problem in IT: the percentage of technology leaders who were women and were interested in being the Chief Information Officer (CIO) has remained steady over the past three years and the number of overall women technology leaders has risen the past five years from 33\% to $40 \%$ (Brown, 2013). However, bias within the pipeline does play a role: according to Clark (2013), "At present, we can assume that because CIO jobs are often filled with candidates who come from male-dominated disciplines, a bias exists in the pipeline that needs adjustment" (p.5).

Very little research exists on leadership in the higher education IT field. In recent years however, there have been studies investigating women CIOs, the role, and the pathways to leadership. Colwill and Townsend (1999) noted that the role of CIO today “ ... is as much about building relationships as IT systems” (np). Clark (2012, 2013) posited that the elements that hinder women's aspirations to leadership in IT include perceived masculine work environments, leadership bias, 
discrimination, a perceived incongruity between being a woman and being in a position of leadership in IT, and a lack of role models and mentors in the field.

\section{Gender and Leadership}

Research on gendered aspects of leadership can provide context for understanding the under-representation of women in technology. Research indicates that the career path and professional experience of women is different and impacted by sexism and double standards, affecting our understanding of leadership and organizational culture. The common metaphor of the glass ceiling, for example, introduced first in 1986 , poses a challenge in that it implies that all women have equal access to lower positions until they all hit the glass ceiling (Hoyt and Simon, 2016). The metaphor of a "labyrinth" has also been used to describe the ways in which women transcend the leadership ladder (Eagly \& Carli, 2007).

Historically, literature on gender and leadership tended to focus primarily on style, traits, gender role perceptions and stereotyping (see Carless, 1998; Cuadrado, Morales, and Recio, 2008; Eagly \& Karau, 2002; Sczesny, Bosak, Neff \& Schyns, 2004; and Sczesny, 2003 as examples). Research showed that women were more likely to engage in participatory, relational, interpersonal and transformational leadership, also described as democratic leadership (Northouse, 2015), which includes attention to " ... self-determination, inclusiveness, equal participation, and deliberation" (Gastil, 1997, p.158) as well as the empowerment of others, distribution of responsibilities, building consensus, and establishing buy-in.

While there has been significant research on gender and leadership over the years, Hoyt and Simon (2016) assert that the current primary research questions regarding gender and leadership still include fundamental questions such as: 1 ) "Do men and women lead differently"?, 2) "Are men more effective leaders than women?", and 3) "Why are women underrepresented in elite leadership roles?" (p.398). Much research on leadership has attempted to address considerations of questions \#1 and \#2 above. Popular leadership literature in the 1980 and 1990 s claimed that women leaders were less hierarchical, 
more cooperative, and more collaborative. Eagly, Makhijani, and Klonsky's (1992) meta-analysis of gender and the evaluation of leaders described that successful women leaders defined success in terms of the accomplishments of others including through facilitating the work of team members, removing barriers, and serving as a mentor; women are more likely to take others' view into account (Eagly, 2016). Eagly and Johnson (1990) in the first systematic meta-analysis of gender differences in leadership as well as Eagly, Makhijani, \& Klonsky (1992) referred to this team style of leadership as "expressive", "communal" and/or "participative". Meta-analyses therefore show women on average are more likely to be democratic, collaborative and participative, whereas men are more likely on average to be autocratic and directive (Eagly, 2016). Women are also more likely to clearly state expectations, express thoughts and have open communication styles (Kabacoff, 1998) as well as use more positive incentives and place more emphasis on developing positive relationships (Eagly, 2016).

However, more recent literature shows evidence that while sex-related differences are present in leadership style, the differences are small (Eagly \& Johannesen-Schmidt, 2007). It may be, instead, that women and men differ more in their values and attitudes than their actual styles of leadership: "Women ... enact their leader roles with a view to producing outcomes that can be described as more compassionate, benevolent, universalistic, and ethical, thus promoting the public good" (Ayman, Korabik \& Morris, 2009, p.8). Dominici, Fried, and Zeger (2009) describe that male, transactional and hierarchical models of leadership are still the current standard, whereas women are more likely to use transformational leadership and contingent rewards in the United States as well as in Australia, New Zealand, Canada, and the United Kingdom (Baker, 2016, Carless, 1998; Hoyt \& Simon, 2016). Ayman, Korabik and Morris (2009) examined the perception of transformational leaders, who are leaders that act as inspirational role models, work to develop skills in their followers, and motivate their followers. Women leaders are more participatory, relational and interpersonal and tend to have more collective views of leadership (Ayman, Korabik \& Morris, 2009), however, it is not always beneficial to be a participative leader and the advantages of which often depend instead on context (Gastil, 1997). 
The "double bind" of leadership for women. While women leaders are rated higher on measures of transformational leadership than male leaders (Ayman, Korabik \& Morris, 2009; Eagly, Johannesen-Schmidt \& van Engen, 2003), sexism continues to have negative consequences for women in leadership positions, a phenomenon referred to by Catalyst (2007) as a "double bind". There are in fact differing norms about leaders that are gendered: women are expected to be pleasant and caring; men strong and assertive (Eagly, 2016).

Ayman, Korabik \& Morris (2009) found that men may not accept transformational leadership from women as easily as from men. Instead, the gendered perceptions of leaders result in differing expectations: “ ... normatively people think that women should specialize in these culturally feminine behaviors and that men should manifest the more charismatic aspects of transformational leadership, which are associated with higher positions in organizational hierarchies" (Ayman, Korabik \& Morris, 2009, p.5). Similarly, women leaders who conform to feminine stereotypes are described as "too soft" and those who conform to masculine stereotypes are considered "too tough" (Catlyst, 2007). Eagly and Johnson's (1990) meta-analysis on gender and leadership revealed that men do adopt more top-down leadership styles, but more significantly, definitions of successful leadership are gendered in two specific ways: women and men who are effective are expected to demonstrate different styles, and their assessments differ as to what it means to be successful leaders.

\section{Understanding the "why" of underrepresentation of women} leaders. Finally, a consideration of Hoyt and Simon's (2016) final question, "Why are women underrepresented in elite leadership roles?" reveals scant support for commonly-held notions that women receive less education than men, they quit their jobs more often, or opt out of leadership track for family, but rather researchers have found that women have less work experience and more career interruption than men (Hoyt \& Simon, 2016). Hoyt and Simon (2016) and Clark (2013) posit that we will see more women in elite leadership roles - if more equitable social changes take place including more mentoring opportunities for women, greater gender equity in domestic responsibilities among men and women, and when women have greater negotiation 
power. Sexism persists within the context of higher education as well, where research tends to agree with existing literature on gender and leadership more broadly in that women leaders see success as a team effort (Dunn, Gerlach \& Hyle, 2014), emphasize collaboration, frequent communication, and shared information when creating a vision (Gale, 1998; Reinarz, 2002; Steward, 2009), and that women leaders interpret effective leadership differently than men (Eagly \& Johnson, 1990; Wolverton, Bower \& Hyle, 2009).

\section{Organizational Culture in Higher Education}

An understanding of organizational culture can help make sense of a complex phenomenon such as the lived experiences of the women in this study. All organizations have a culture - an increasingly important aspect for leaders to consider when implementing change. The organizational cultural (or "symbol") frame identified by Bolman and Deal (2013) in their seminal work allows for a focus on how institutional elements such as values and beliefs affect institutional functions (Clark, 1970; Deal \& Kennedy, 2000; Koprowski, 1983; Kuh \& Whitt, 1988; Tierney, 1992; Zucker, 1988); these values and assumptions guide an organization and its members and provide the foundation within which the organization and its members function.

Within higher education, organizational culture can be found in institutional history, mission, historical place, and the stated or unstated assumptions about who the institution is meant to serve. An institution's sense of historical place and the stated or unstated assumptions about whom it is meant to serve may impact leaders' experiences; culture defines what higher education leaders are able to do (Zenk, 2014).

Information technology's organizational culture. Little research exists on the culture of higher education IT organizations and how that affects men and women in the profession. In 2013, Clark authored a research report for EDUCAUSE titled Gender Diversity among Higher Education CIOs, which was the first such report to consider organizationallevel components that may contribute to the lack of women rising to the position of an academic CIO. Clark's (2013) study affirmed the masculine culture of IT and found that culture "... explained the masculine 
discourses that communicate norms for IT environments, while underscoring factors related to women's attainment of this top IT job" (p.21).

Historically, when the field of IT was founded, leaders were seen as needing to possess very technical skills that were not accessible to other members of the organization. IT was not supposed to be accessible to the everyday person; it was for the experts: "Control and power over resources rested in the hands of these professional males. They were surrounded by mystique, which suited both the information technology professionals and the rest of the management structure (also mostly males)" (Colwill \& Townsend, 1999, p.211). For years there has been a perceived inaccessibility of IT, centering on what Clark (2012) describes as "men and their machines". Women in the IT field played supporting and secondary roles from the start: "The information technology professionals liked being behind the technological curtain as it allowed them to retain control (power)." (Colwill \& Townsend, 1999, p.211). Clark (2012) argues that because of the history of the discipline, while the IT field has matured, the evolving "cultural discourse" in the profession has been masculine. This finding is supported by other research that has suggested that when a field has a history of strong ties to one gender, the occupations within that field are informed by the values and commonly held assumptions of that gender (Acker, 1990; Ely \& Padavic, 2007). This paper builds upon Clark's (2013) work and examines the first-hand experiences of women leading IT projects through a lens of organizational culture.

As detailed above, the existing literature on gender and leadership tends to focus primarily on style, traits and gender role perceptions and stereotyping, while the research on gender and leadership within IT in academia is scant. What is relevant yet missing from the current scholarship is the intersection of these areas with organizational culture. Universities in particular can have very established organizational cultures that may or may not contribute to the success of leaders, and an examination of this intersection can help to explain the experiences of women who are currently underrepresented in the highest levels at institutions. Through use of an institutional cultural lens we are able to examine how aspects of the culture set the stage for the experiences of women leaders in technology. 


\section{Methods}

To examine the experiences of women leading technology initiatives in an organizational context, we conducted a qualitative, comparative case study which allowed for both the understanding of the processes at two institutions (within-case) as well as for comparison of this phenomenon across institutions (cross-case) (Merriam, 1998). The following research questions were considered:

1. What is the experience of women academic leaders at public universities in the leadership of technology-based projects?

2. How do others perceive women academic leaders at public universities in leading technology-based projects?

\section{Data Collection and Analysis}

The identification of cases for this study was conducted through purposeful sampling based on the following criteria: 1) all campuses within one public university system in a single state, 2) all campuses undergoing an institution-wide technology change related to the academic core, and 3) all campuses' technology change initiatives being led by a woman. Selecting cases from one public state system allowed for the ability to control for state-specific constraints and political factors that can vary significantly from state to state. Five participants were included across two campuses including: 1) the leader of the technology initiative, and 2) 1-2 additional members of the implementation team including at least one specialist in IT (see Table 1). While we did not specifically seek out only women implementation team members as part of our selection criteria, it is notable that all additional team members identified were also women.

Data in this study consisted of transcripts from five interviews (openended, semi-structured questions). Participants were asked to reflect on the technology initiative and their role in the implementation, their perceptions on the way the project was led, and the extent to which it was similar or different to the way other initiatives are begun at the institution. Participants were also asked to describe their experiences of how institutional culture is articulated at the institution (implicitly and explicitly), and how they would describe institutional values. 
Table 1. Number and Type of Study Participants

\begin{tabular}{lccc} 
Institution & $\begin{array}{c}\text { Project } \\
\text { Leader }\end{array}$ & $\begin{array}{c}\text { Implementation } \\
\text { Team Member(s) }\end{array}$ & $\begin{array}{c}\text { Chief Information } \\
\text { Officer (CIO) }\end{array}$ \\
\hline Institution A & 1 & 2 & Female \\
Institution B & 1 & 1 & Male \\
\hline
\end{tabular}

All interviews were conducted via telephone and were recorded and transcribed verbatim. This study was approved by the appropriate Institutional Review Board.

Data analysis was conducted with the use of NVivo. The researchers did descriptive coding and thematic coding initially to determine and create major node categories in response to the research questions posed. Analytic coding was then conducted to create node hierarchies and compare data to emerging themes by analyzing and developing interpretive categories following each case. Through use of NVivo the researchers then conducted both within-case and cross-case analyses by analyzing the nodes through the frequency and sources with which they appeared within each campus (within-case) and across each campus (cross-case). The approach to data analysis drew from grounded theory and constant comparative analysis (Creswell, 1998).

\section{Trustworthiness of Findings and Limitations of the Study}

The trustworthiness of the findings of this study is strengthened through the use of "rich and thick descriptions" (Merriam, 1998, p. 211), lending to the transferability of findings to other contexts. Through use of description, others are able to determine the extent to which the results may apply to their own experience. Trustworthiness is also strengthened through dependability including detailed description of the data collection, interpretation, and analysis (see following section).

While several steps were taken in an attempt to increase the trustworthiness of this study, limitations do exist. First, we acknowledge our study was conducted by using five participants within one singular state. While this decision was intentional for the study design in order to control for variables and political factors that can change from state 
to state, it also limits the extent to which the results can be generalized within other institutions in other state contexts. Finally, it is important to acknowledge that as a qualitative study it is difficult to prevent personal bias both as researchers and for our participants; we each have our own world views that as researchers can impact our research, interviewing skills and analysis and for participants can impact their articulation of their experiences.

\section{Research Findings}

Within-case analyses suggest that women are very aware of the gendered environment within which they lead and that they believe the masculine nature of male-led IT organizations create an environment that feels different from the rest of the institution. Thematic cross-case analysis suggests that women leading technology initiatives see themselves as negotiators, translators, and bridge-builders while other team members perceive the leaders as team-oriented and attentive to stakeholders and collaborators.

\section{Within-Case Analysis}

Awareness of gendered environment.

The whole gender thing with IT ... I don't know if I'm going to say this word right, but [there was] a real patriarchy going on. It was like, 'okay, little girl, you go take care of that.' That kind of attitude ... They didn't see our contribution as an important thing.

At Institution B, where the $\mathrm{CIO}$ is male, participants had a crisp awareness of the impact of gender. Participants described an IT environment characterized by extreme examples of gender inequality and a significant use of pejorative language regarding women. The participants cited their experience of working on this IT project as surprising given their expectations that the culture would be different at an institution that was founded by a woman and where they had observed other successful woman-led projects. The same participant described how this 
culture in her experience was in sharp contrast to her experience in private industry:

... the only other place I really have to compare to is the bank, and at the bank, women were equal to men. At least in the groups, the IT groups that I worked in, we weren't considered to be less.

At Institution B, leaders described an IT culture in which women were relegated to taking notes, running errands, and doing executive assistant tasks:

... the CIO utilized [the director] like an administrative assistant. So there's no respect there. And that showed for the rest of the organization. However, the males that he brought in ... he didn't micromanage, they had more weight, they weren't required to take notes at the meeting and tell him what happened. She [the director] is a very well compensated administrative assistant.

Participants used words such as "not valued", "isolated", "ignored", and "distanced" to describe how they were treated from the IT department.

While the participants at Institution A had a much different experience in their IT unit, they also had a crisp awareness of the impact of gender in their workplace, but through a very different experience. At Institution A, participants described a culture that was supportive, led by a woman Chief Information Officer (CIO), including support in gaining pay equity:

I certainly feel like I've had a voice given my current organization structure ... [My supervisor] went to bat for me to get me salary equity because she ... saw a pretty glaring equity issue between my ... role and another gentleman in [a similar role] ... they did work to compensate and make sure that the salaries were equitable ... it was something that she really fought for. 
Leaders at Institution A felt supported not only from the woman CIO in their unit, but also from other male colleagues in IT who acted as allies throughout campus: “... my [project] lead ... will sometimes speak up in support of me ... if he feels like I'm not being heard or not being respected."

Distinct missions. The IT culture of Institution B was not one of relationship building or teamwork, but rather one of function and accountability detached from the overall academic mission of the university. According to one participant at Institution B: "[IT was] very divorced from the fact that [they are working at a university] ... yeah, the server has to be running, but it has to be running to something that serves some value to somebody". This divergence of cultures between the Institution $\mathrm{B}$ and IT was a considerable source of frustration for participants and is discussed further in the discussion (see "A Collision of Cultures"). This experience is also in sharp contrast with the institutional culture at Institution A which is described as "family" by all participants:

... it truly does have a unique comradery, closeness. It is like a family and we very much pride ourselves on that aspect of it ... and that is extended to not only students but also, you know, staff and faculty as well.

\section{Cross-Case Analysis}

Women as negotiators, translators and bridge-builders. The women interviewed were asked to characterize their leadership within the broader context of the university. Participants recognized they are performing as negotiators, translators and bridge-builders and articulated these unique skill-sets as being key components to their role in leading the project discussed. In their role as negotiator, one participant described:

I had to walk in both worlds [IT and the rest of the university] ... I needed to ... make sure that everything my ... client ... needed to have was in place so that they could successfully utilize the product. And that meant working with everybody 
on the IT side to make sure I understood what they needed me to get to them, back and forth. So I was more of a negotiator. I had to kind of speak both languages.

The role of negotiator implies a zero-sum game - that there is one thing the client wants, and another thing that IT wants - and each needs to give something up in order to be successful. Similarly, as translators, the women leaders understood the importance of having an outward face and being receptive to their client needs, while translating technical speak to a less technical audience:

There's a difference in what I'm doing on this side of the project [as the leader] ... and what that core IT group is doing. I'm coming to them because I need programming changed ... that's definitely their skillset. [But as the leader] I'm going to be analyzing the business process, analyzing what the end user needs, mapping out those facts, and then doing the heavy testing.

Finally, women leaders demonstrated bridge-building by placing an emphasis on getting buy-in; they wanted everyone at the table, and wanted people to feel like it was "their" product. One participant described: "I put together a committee of people from across the campus who I thought were key stakeholders," while another commented on the widespread campus involvement: "I feel that we're getting the collaboration of the entire university ... Everyone is invested in the development of the product." This finding is consistent with the institutional values of shared governance expressed by participants and common in institutions. As bridge-builders, the experience of these leaders is also consistent with current literature that tells us that women tend to have more democratic and participatory leadership styles (Eagly, 2016; Eagly \& Johnson, 1990; Eagly, Makhijani \& Klonsky, 1992; Kabacoff, 1998; Northouse, 2015). What is notable is the extent to which this quality was important for all women leaders in the study, and across all institutions.

Women as collaborators and mentors. Participants were asked to describe the ways in which the technology initiative was led. Findings 
suggest that team members perceive the women leaders as being teamoriented, and that the women leaders attribute their success to others, specifically to fellow co-workers and mentors. Effectiveness was due to being part of a team as described by several participants:

It has been so much of a team effort ... I'd almost say that I'm more of an organizer ... it definitely is a collaboration of all of us.

Part of what she did was there was a committee of campus users and administrators ... more of a working group.

Everyone works so well together as a team.

While team members described the women leaders as team-oriented, the leaders themselves were much more modest, attributing much of that success not only to the teams but also to the fact that they were following women mentors or prescribed ways of operating within the institutional context. One participant described:

I wasn't exposed to any other leadership styles ... I learned most of what I know from [my mentor at the university] ... I saw her being successful" while another participant similarly commented: "I have such great role models in our leadership.

The notion of modeling the leadership style of a mentor was particularly important for one participant who had witnessed a failed initiative and was particularly attentive to leading in a way congruent with the institutional culture:

We had a technology implementation that failed previously ... it was handled with a smaller group that didn't consult broadly ... we learned from that experience ... people lose confidence.

The findings in this study suggest that leaders exercised a team-oriented approach because they saw a model of where this was effective, learned from failures they witnessed, and followed the examples of others who had been successful in operating within the organizational norms. 


\section{Discussion: A Collision of Cultures}

The stories of the lived experiences of the women in this study point to a higher-level narrative that describes a collision of cultures between Information Technology and higher education, particularly when CIO leadership is male. Findings suggest elements of culture within the IT field that contribute to the experiences of women leaders in IT, and leading a technology project may add a layer of gender expectations and gender roles that are more entrenched in the IT world. Findings also suggest a collision of cultures between the culture of IT and the overarching university culture that was described by all participants interviewed. One participant described: "IT, in my opinion, thinks that it is an IT company that happens to have a university hanging around it", suggesting that IT doesn't adhere to institutional cultural norms but rather lives outside of the institutional higher education culture. A participant hypothesized this cultural clash exists due to the masculine historical origins of the IT field:

I think technology helped [drive a] wedge [between cultures] ... because it's such a scary thing for people ... And they get away with that because they're IT and people are scared, you know, it's technology, let's just let them handle it, you know. I think wholeheartedly that's why they get away with it. As long as the chancellor sees things up and running, everybody's good. Nobody thinks about that. And that's how they behave over there.

This finding lends evidence to the stories told on the history of the IT field, which was not a field originally accessible to the average person until the invention of the personal computer. As Colwill \& Townsend (1999) described, "The information technology professionals liked being behind the technological curtain as it allowed them to retain control (power)" (p.211).

\section{Implications}

While this study investigated women leading technology initiatives that were not necessarily in IT organizations themselves, the results of this 
study reinforce the notion that gender matters, especially for women navigating within and intersecting with IT organizations. Literature on institutional change reminds us that change processes and the ability to successfully implement change depend on a successful understanding of organizational culture. Kezar (1994) contends that modern leadership research often ignores subtleties and context and instead provides overarching global strategies that may not be useful in changing situations. We make a mistake if we don't pay attention to the gendered nature of our institutional cultures and the climate of leadership that exists, and we will lose good leaders in the process. As we saw in the case of Institution A, leadership continues to be important in establishing institutional culture, and the influence of gender at the CIO level matters to the lived experiences of these female project leaders. Those who do choose to stay understand the cultures they are in and learn to navigate within them.

Results of this study are important for institutional leaders, directors and faculty interested in institutional leadership and gender, and reinforce that success as leaders requires an understanding of and attention to institutional culture. By exploring gender dynamics among leaders in an organizational context, this paper investigates the experiences of women to help lend further explanation to the dearth of women leaders in high-level positions at colleges and universities and further contributes to Clark's (2013) call for research on the characteristics of organizational cultures that contribute to women's success as leaders within IT.

\section{References}

Acker, J. (1990). Hierarchies, jobs, bodies: A theory of gendered organizations. Gender \& Society, 4(2): 139-158.

Ayman, R., Korabik, K., \& Morris, S. (2009). Is transformational leadership always perceived as effective? Male subordinates' devaluation of female transformational leaders. Journal of Applied Social Psychology, 39, 852-879.

Baker, M. (2016). Women graduates and the workplace: Continuing challenges for academic women. Studies in Higher Education, 41(5), 887-900. 
Bichsel, J., \& McChesney, J. (2017). The gender pay gap and the representation of women in higher education administrative positions: The century so far. Research report. Knoxville, TN: CUPA-HR. Retrieved from https://www.cupahr.org/surveys/briefs.aspx

Bolman, L. G., \& Deal, T. E. (2013). Reframing organizations: Artistry, choice, and leadership, $5^{\text {th }}$ ed. San Francisco, CA: Jossey-Bass.

Brown, W. (2013, June 18). In higher education, fewer women graduate to CIO [article]. Retrieved from Information Week http://www.informationweek.com/government/leadership/ in-higher-education-fewer-women-graduate-to-cio/d/d-id/1110417

Carless, S. A. (1998). Gender differences in transformational leadership: An examination of superior leader, and subordinate perspectives. Sex Roles, 39(11-12), 887-902.

Catalyst. (2007). The double-bind dilemma for women in leadership: damned if you do, damned if you don't. Retrieved from: http://www. catalyst.org/knowledge/double-bind-dilemma-women-leadershipdamned-if-you-do-doomed-if-you-don $\% \mathrm{E} 2 \% 80 \% 99 t$

Center for Higher Education CIO Studies (2013). In higher education, fewer women graduate to CIO. Retrieved from: https://www.informationweek.com/government/leadership/ in-higher-education-fewer-women-graduate-to-cio/d/d-id/1110417

Clark, E. (2013). Gender Diversity among Higher Education CIOs. Research Report. Louisville, CO: EDUCAUSE Center for Analysis and Research, September 27, 2013, available from: http://www.educause. edu/ecar.

Clark, E. (2012). Women CIOs in higher education. Research Bulletin. EDUCAUSE Center for Applied Research, October 16, 2012, Retrieved September 7, 2016 from: https://library.educause.edu/ resources/2012/10/women-cios-in-higher-education

Clark, B. R. (1970). The distinctive college: Reed, Antioch, and Swarthmore. Chicago, IL: Aldine Publishing.

Colwill, J. \& Townsend, J. (1999). Women, leadership and information technology: The impact of women leaders in organizations and their role in integrating information technology with corporate strategy. The Journal of Management Development, 18(3), 207-215.

Creswell, J. W. (1998). Qualitative inquiry and research design: Choosing among five traditions. Thousand Oaks, CA: SAGE Publications, Inc. 
Cuadrado, I., Morales, J., \& Recio, P. (2008). Women's access to managerial positions: An experimental study of leadership styles and gender. The Spanish Journal of Psychology, 11(1), 55-65. Retrieved from ProQuest Central. doi: 1910055741

Deal, T. E., \& Kennedy, A. A. (2000). Corporate cultures: The rites and rituals of corporate life. New York: Basic Books.

Dominici, F., Fried, L.P., \& Zeger, S. (2009). So few women leaders: It's no longer a pipieline problem, so what are the root causes? AAUP online. Retrieved May 30, 2016 from: https://www.aaup.org/article/ so-few-women-leaders\#

Dunn, D., Gerlach, J.M., \& Hyle, A.E. (2014). Gender and leadership: Reflections of women in higher education administration. International Journal of Leadership and Change, (2) 1, 9-18.

Eagly, A.H. (2016). What does social science say about how a female president might lead? The Conversation. Retrieved online: January 2, 2019 from: http://theconversation.com/what-does-social-science-sayabout-how-a-female-president-might-lead-61255

Eagly, A. H. \& Carli, L. L. (2007). Through the labyrinth: The truth about how women become leaders. Boston, MA: Harvard Business School Press.

Eagly, A.H. \& Johannesen-Schmidt, M. (2007). Leadership style matters: The small, but important, style differences between male and female leaders. In D. Bilmoria \& S.K. Piderit (Eds.), Handbook of women in business and management (pp.279-303). Northampton, MA: Edward Elgar.

Eagly, A.H., Johannesen-Schmidt, M.C., \& van Engen, M. (2003). Transformational, transactional, and laissez-faire leadership styles. A meta-analysis comparing women and men. Psychological Bulletin, 129, 569-591.

Eagly, A.H., \& Johnson, B.T. (1990). Gender and leadership style: A metaanalysis. Psychological Bulletin, 108, 233-256.

Eagly, A. H., \& Karau, S. J. (2002). Role congruity theory of prejudice toward female leaders. Psychological Review, 109, 573-598.

Eagly, A.G., Makhijani, M.G., \& Klonsky, B.G. (1992). Gender and the evaluation of leaders: A meta-analysis. Psychological Bulletin, 111, 3-22.

Ely, R.E. \& Padavic, I. (2007). A feminist analysis of organizational research on sex differences. Academy of Management Review, 32(4), $1,121-1,143$. 
Gastil, J. (1997). A definition and illustration of democratic leadership. In K. Grint's Leadership: Classical, contemporary, and critical approaches. New York, NY: Oxford University Press.

Gale, L.L. (1998). Gender and leadership: The implications of small group research. Initiatives, 57(4), 19-26.

Hoyt, C.L. \& Simon, S. (2016). Women and leadership. In P.Northouse's Leadership: Theory and practice, $7^{\text {th }}$ ed. Thousand Oaks, CA: Sage.

Johnson, H. J. (2016). Pipelines, pathways, and institutional leadership: An update on the status of women in higher education. Washington, DC: American Council on Education.

Kabacoff, R. (1998, August). Gender differences in organizational leadership. A large sample study. Paper presented at the $106^{\text {th }}$ Annual Convention of the American Psychological Association, San Francisco, CA.

Kezar, A. (1994). Leadership challenges at urban and metropolitan universities: Communities, stakeholders, money, diversity, and change. Leadership in Metropolitan Universities, 5(3), 6-9.

Koprowski, E. J. (1983). Cultural myths: Clues to effective management. Organizational Dynamics, 12(2), 39-51. doi:10.1016/oogo-2616(83)90032-3

Korn Ferry (2019). Korn ferry analysis of largest U.S. companies shows percentage of women in c-suite roles inches up from previous year. Retrieved from: https://www.kornferry.com/press/korn-ferryanalysis-of-largest-us-companies-shows-percentage-of-women-in-csuite-roles-inches-up-from-previous-year?mod=article_inline

Kuh, G., \& Whitt, E. (1988). The invisible tapestry. ASHE ERIC Higher Education, Report No. 1. Retrieved from http://files.eric.ed.gov/ fulltext/ED299934.pdf

Merriam, S. B. (1998). Case study research in education: A qualitative approach. San Francisco, CA: Jossey-Bass.

National Center for Women \& Information Technology (2019). Programs. Retrieved January 1, 2019 from: https://www.ncwit.org/

Nidiffer, J. (2002). Overview. In A.M. Martinez Aleman and K.A. Renn (Eds.), Women in higher education (pp.101-131). Albany, NY: State University of New York Press.

Northouse, P.G. (2015). Leadership: Theory and practice (6 $6^{\text {th }}$ ed.). Thousand Oaks: CA. Sage. 
Reid Sarkees, M. (2008). Where have all the leaders gone, and how can we bring them back? On Campus With Women, 37 (1). Association of American Colleges and Universities. Retrieved from: http://archive. aacu.org/ocww/volume37 1/feature.cfm?printer friendly=1

Reinarz, A.G. (2002). Issues for women in higher education administration. The Academic Advising News, 25(4).

Sczesny, S., Bosak, J., Neff, D., \& Schyns, B. (2004). Gender stereotypes and the attribution of leadership traits: A cross-cultural comparison. Sex Roles, 51(11-12), 631-645.

Sczesny, S. (2003). A closer look beneath the surface: Various facets of the think-manager--think-male stereotype. Sex Roles 49(7-8), 253-262.

Steward, J.M. (2009). Common characteristics of women leaders in higher education administration (Master's thesis). Department of Planning, Public Policy and Management, University of Oregon, Eugene, OR.

Tierney, W. G. (1992). Cultural leadership and the search for community. Liberal Education, 78(5), 16-21.

Wolverton, M., Bower, B., \& Hyle, A.E. (Eds.). (2009). Leading ladies: Presidents and policy makers in higher education.

Woo, M., \& McIntosh, K. (2016, May 02). Diversity, equity, and inclusion: A call to action [article]. Retrieved from Educause, September 3, 2016: http://er.educause.edu/articles/2016/5/ diversity-equity-and-inclusion-a-call-to-action

Zenk, L.R. (2014). Past, present, future: The role of mission and culture in higher education institutions. (Unpublished doctoral dissertation). University of Minnesota, Minneapolis.

Zucker, L. G. (1988). Where do institutional patterns come from? Organizations as actors in social systems. In L. G. Zucker (Ed.), Institutional Patterns and Organizations; Culture and Environment. Cambridge, MA: Ballinger. 